\title{
Typical Female Images in Chinese Operas and their Singing Style
}

\author{
Qi Chen and Hui Xu \\ College of Music ,Jiangxi University of Technology
}

Keywords: Chinese opera; Typical female; Character image; Music style; Singing style

\begin{abstract}
As an artistic form combining Western music culture and local culture, Chinese operas have gone through a tough way in its development for less than one hundred years. Until today, against the background of the glorious history of European and Western operas, China's national opera is making indomitable progress and innovation with its tender pace. Herein, part of the typical operas is worthy our careful scrutiny, especially the attention of our vocal music professionals. As is known to all that it is the fundamental task of opera performance to create stage images with flesh and blood, and there is no opera without images. Taking different types of temperament as the basis for division, this paper analyzes the creation of typical female images in Chinese operas, and elaborates on the contrast of singing styles to the creation of images while focusing on analyzing the singing part of several representative females in operas.
\end{abstract}

\section{Introduction}

"Opera image is the most basic and core proposition for no matter theoretical research and creation, performance and appreciation. Without the discussion and creation of opera image, it is hard to state a series of problems about the contents and forms of operas, all frameworks of the opera art lose their fulcrum of force, and the so-called nature of operas becomes shells without a soul. In this sense, to master the characteristics of character images in each opera means to master the characteristics and historic significance of operas. Opera plot, dramatic conflict, revelation of characters' personalities, organization of climax and the organic combination of various artistic factors as well as the comprehensive application of various artistic means should finally be embodied as images. Opera image is a kind of comprehensive artistic image while as an important element of opera, the creation of character images determines the success of literary and artistic works.

Chinese operas are a unique form of art combing China's local music art and the opera art after it was introduced to China in the early $20^{\text {th }}$ century. It is a broad concept of music and opera developing on the basis of combing various forms of art like China's folk music (especially opera music and dancing music) and foreign operas, and it is also the results of combing and blending Chinese and Western operas and music. As the artistic form combing Western music and China's local music, Chinese operas have gone through a tough way in their less than one hundred years of development. Throughout the more than half a century for the survival and development of Chinese operas, it is full of twists and turns. Until today, against the background of the glorious history of European and Western operas, China's national opera is making indomitable progress and innovation with its tender pace. Herein, part of the typical operas is worthy our careful scrutiny, especially the attention of our vocal music professionals.

Research of Chinese operas has always been the concern of music researchers. After the nearly one century of opera art's tough development in China, hundreds of opera works have been produced. 
Although the good and bad are intermingled, these artistic practice have laid a solid foundation for the existence and development of Chinese operas nowadays and in the future as well as made beneficial exploration to form opera art with Chinese characteristics. In this process, although its development has obtained major opportunities, it is also faced with numerous difficulties. All of these further promote music fans to carry out lasting research into the spiritual culture of Chinese operas and pay more attention to the creation of female images in Chinese operas.

There are different interpretations of images under different temporal and spatial trends, and relying on female images of different temperaments, this paper analyzes the creation of their images from their singing styles with profound practical significance for us to get to know the current survival of Chinese operas and stimulate opera learners get to know excellent traditional culture of their nation from a broader sense.

This paper, mainly analyzing the image characteristics and singing styles of classical females in Chinese operas, is divided into two parts: in the first part, different temperament types will be taken as the basis to summarize the representative, true and complete classical female images in Chinese operas into three types: Tragedy \& Great Suffering and Hatred, Hero \& Revolutionary Struggle, Love \& Emotion-First, and then elaborates on the temperamental characteristics of these three types of female images as well as summarizes the common points of these three images to demonstrate that they can be transformed mutually while breaking the background of the time. The second part elaborates on the role of music factors and opera conflict factors in the creation of opera images. Music factors and opera factors are the two basic construction materials of the opera complex, and both of them play a decisive role in creating opera images. Therefore, both of them should be considered in analyzing figure images and the research should be carried out with the view of dialectical unity.

\section{Characteristics of Typical Female Images in Chinese Operas}

Opera is a very comprehensive performing art, and it can only demonstrate the entire theme through a series cooperation of performance, choreography, lighting, costumes and makeup. However, in the final analysis, the fundamental task of opera performance is to create stage characters with flesh and blood. There is no opera without characters because the theme of any opera is demonstrated through character images.

For almost all Chinese and foreign operas, each opera composer relies on scripts while using music to render the story and create characters. In terms of this, opera is the same as other theatrical arts (e.g. drama, dance). In order to create complete characters, we should first get to know characteristics of the character, that is, authenticity, representativeness (typical) and integrity.

Image authenticity. Real image (not unrealistic) is the art of life, and any unrealistic opera character image or scene image is not artistic. Performers sing an aria of the opera, to pursue the real image of opera, both characters, or landscape image, must have the authenticity of real life, otherwise the image will be created in empty boredom, lack of life, it is difficult to move the audience.

Image representation. Opera art images must be representative of the real, which is typical. Typical image of authenticity is based on the artistic process, to make it more representative. Opera performers in addition to faithfully interpret every Recitative, Aria, and playwright wrote the art of image processing will make the character continuously enriched, more typical. 
The integrity of the image. Performers Create a good image of the Opera is based on the stage of life experience, to be conceived with blood. Opera both in China and overseas, regardless of Recitative, Aria, Ensemble, shaped the image should be an organic whole, may have the image of character, human nature, temperament and temperament. Image integrity is mainly in character images. Singing in the cavity is a Word from the characters personality, must conform to the characteristics of the image of every phrase. Images throughout the whole Opera from the beginning to the end, and we should pay attention to the integrity of the image.

Character image plays a major role in opera and is the core of this vocal art image system of opera. Characters in the Opera, not only shape the character's voice, and character features. Through these descriptive characterizations, reveal the spiritual world of the characters, and show you the dramatic conflict.

In addition to paying attention to creating character images, opera works also focus on describing natural scenery because people live in social environment and natural environment, and to create character images cannot go without describing the environment and scenery. Description of good environment and natural scenery can tell the background, time and location of the incident and also demonstrate the identity, thought, virtues, personality and hobby of characters to some extent. Especially, play writers usually create a classic living environment according to the character's personality and development of the plot so as to serve for creating character images. There are many instances in this regard: the scene of "North Wind Blowing" in "White-haired Woman", the part "Honghu Water, Waves after Waves" describing the natural scenery and lives of people in the revolutionary base areas in "Honghu Red Guard"; the solo part "Clear Water and Blue Sky" in "Xiaoerhei Gets Married"...All of these reflect the characters' inner world and mood through describing natural images so as to perfect the creation of character images.

\section{Female Images with Different Types of Temperament}

Chinese operas still occupy the mainstream in creating female characters, and among the not so many opera works handed down from the nearly one hundred years in the 20th century as well as those still sung among people, females still occupy the vast majority. It is easy to see that this is the result of artists' compassionate, mercy and love for women who have been living at the grassroots of the society for a long time with the awaken of modern consciousness, and it is also the results of women's self liberation. For classical female characters created by Chinese operas, the author has a superficial understanding that each character is inseparable with the background of creating operas, including social background and the background of the age. However, according to types of temperament, these classical characters can be roughly divided into three types:

Tragedy \& Great Suffering and Hatred. Representative of this type is Xier (heroine in the opera "White-Haired Women".

Female character is always a remarkable sign in the development of Chinese operas. From the mid 1940s to the mid 1950s, aesthetic principles and basic features of Chinese operas have already been formed, and this is the foundation of Chinese national operas with the famous "White-haired Women" played by a female character as the mainstream style.

The emergence of "White-Haired Women" not only brings Chinese operas to a golden road suitable for its unique development direction, but also accumulates the rich artistic experience of creating female characters. 
The composer creates the classic music theme according to personalities of different characters, and deepens it with the development of characters' personality and plot changes. This series is the new dance movement and dance dramas were produced on the basis of experience. Its music rooted in deep foundation of Chinese folk music, assimilate and learn some useful experience from foreign opera, boldly made a new creation. Select folk tune on the music and technique, the combination of music and drama of the opera, with distinct characteristics of the times and a national style, is China's first large new opera to a more mature. Nationalization in opera, music drama and music has gained valuable experience on the carved figures. Chinese opera entered a new stage, the opera works also had a profound impact on later.

Hero \& Revolutionary Struggle. After the exploration period in the creation of Chinese operas, a fruitful harvest period arrived. There are sufficient bases to call it as fruitful period. In 1959, the emergence of "Honghu Red Guard" brought the creation of Chinese operas into a "red opera" period. Guided by this work, a number of operas about revolution and fight appeared. While description of female heroism also prospered with an irresistible force.

As heroine of this opera, Han Ying is a strong revolutionary with her sublime heroism and broad mind, courage, and deliberate revolution image infecting and inspiring numerous revolutionaries of the society at that time and also inspired the birth of a number of classic red-themed operas so as to make the creation of operas in China reach the second climax after the "White-Haired Woman".

With the constant emergence of a lot of excellent works, especially the success of "Honghu Red Guard", opera art in new China develops in prosperity and demonstrates a thriving momentum. Female heroes of Chinese operas created during this period of time were unique in female characters of Chinese operas with their positive images being as the epitome of female images in Chinese operas before the Cultural Revolution and becoming the peak that could hardly be surpassed for later creators.

Love \& Emotion-First. As China's first lyric psychodrama, "Regret for the Past" could not be ignored. This drama is a classical work created by China's famous musician Shi Guangnan according to the script of Lu Xun's namesake novel describing a couple of educated youth Zijun and Juansheng during the "May Fourth" period, who broke the barriers of feudal ethical code and got married courageously in the pursuit of free and happy love and life. However, due to the pressure of the old force and hero Juansheng's hesitation, Zijun finally died in hatred and Juansheng began to explore new life with trauma in a tragic end.

In this passionate work full of tension, the composer and screenwriter depicted a number of lifelike characters represented by Jinzi, whose strong desire for freedom and love become intense with the development of the plot. Depressed by her poor living environment, she never loses the belief in a happy life and pursuit for freedom; her yearning for love makes she never give up her inner fire of enthusiasm. She also impressed us a lot with her love-oriented image.

Therefore, these three different types of image can be intertwined and interrelated. Influenced by different social background of different periods, their images gradually go upward towards the deeper female topics while gradually changing the significance of motherland, ideal, life and death to love, family and pursuit, which must be said a bright path to gradually revitalize China's national operas. 


\section{Music Factors' Decisive Role in Creating Character Images}

In Opera, use of all musical elements and every possible means to character, the melodrama, dramatic conflict, and ultimately responsible for music on characters to complete mission-this is the music factor plays a decisive role in this. Obviously, the Germany opera creator Wagner concluded in the 19th century that "Opera is a play with music". The authority of this concept is undoubted. How to treat and deal with the relationship between music and drama in Opera, and have been throughout the world opera composer is writing career has always been the basic motif. Lyric Opera music than narrative significance in the image and cannot be ignored, especially wow lyrical Arias, duets, ensemble, choir and orchestra music to express the character's love life and the secret of mental activity, to depict the image of internal factors play an irreplaceable function of character and charm.

How to understand music is essential factor of decisive significance in the Opera. Take the opera "Jiang Jie" for instance, full drama music to Sichuan folk songs tones material for main tone, and widely absorption Sichuan Opera, and Po drama, and Opera, and hang Beach, and ocean piano, and Sichuan voiceless, and Opera, drama, and rap music of factors be creative of fusion and dramatic of development; throughout full drama of theme song "red Mei praise" and in plays conflict in the of all development changes, draw drama music layout structure and development features writing hero big paragraph sets ARIA, are powerful description has "Jiang Jie" of music image, advance plays contradictions of development. This negative image also gets rid of the music profile, comic mode, and a new creation. "Trial" a heavy use of prose poetry readings and drum accompaniment to present between Shen Yangzhai and the confrontation of good and evil, both dramatic tension and played percussion performance features, makes a dramatic scenes in opera music.

Let us look at another opera "Regret for the Past", opera musical structure of "Sonata principle", through large surface rendering logic of development of music reproduction obtained changes and unity. Strong lyrics and delicate psychological description is a major feature of "Regret for the Past" music. Composers through themes that run through the development of technique, through mass-lyrical-dramatic ARIA, Recitative, romances, ballads and ensemble, chorus and Orchestra Music, reveal the hero and heroine in love tragedy complex psychological and emotional experience, brush strokes and delicate and touching. This shows that the melody is not only the soul of Chinese music, but also the soul of Chinese opera. This is our traditional music, Opera, traditional and contemporary audience's appreciation of the decision. Singing opera if you abandon the melody, it was abandoned by viewers.

In short, the significance of music factor in creating opera performance images is obvious as it is not only related to the depth of creation of images, but also directly determines its success.

\section{Contrast of Styles of Main Singing Part to Character Images}

Music is an art form that cannot specifically show the nature of things, it's not like literature, drama, painting and other arts through many specific descriptions of characters, specific description of shape, not good at showing exactly the concept. However, it is good at deep to expose the inner thoughts and feelings of the characters, vivid, direct, and can follow the different personality of each character to reveal. It can also show different emotions and reflect the same figures for different events and can string together these different emotions, form a complete set of characters, show specific character-specific thoughts and feelings that the music character, portraying characters. Opera is expressed in music theatre, and music is a performance art, it can directly cause people 
emotional experience through Synesthesia, and on this basis with imagination, provokes waves of emotion.

With the various features of the opera, it can play the protagonist's recitative and aria style characteristics to create an image. The author believes that character style characteristic of the main aria comes from the opera the music style and singing style are two aspects to analyze and grasp, which portrayed the more perfect.

\section{Overall Singing Style of Female Images' Main Singing Part}

With the prosperity of Chinese operas, various singing characteristics of Chinese operas have been formed. In general, during the process of forming and developing the female singing style of operas of the above temperaments, strong sense of national awareness is reflected. Art practice of opera performers has provided exploration of creative singing for future singers.

As the famous opera singer Li Guangxi said: "to sing a song, need not only have a good sound image in the mind, and more importantly also works depicting scenes and characters: "produce sound with emotions" and "express true feelings" are the common pursuit of all opera singers. In its essence is singing voice using speed, color change, transformation, articulation of broad characteristics, climatic and comprehensive layout and the use of special techniques, must be based on the works of creative intent, background, content, style, music, basic materials, character, a particular emotional state, ARIA's music performance measures, and in-depth studies on specific issues.

Due to the deepening of opera creation and diversity of character images, there are rich and colorful singing styles of opera: some develop on the basis of national singing, some develop on the basis of traditional operas and some learn from the Western Bel Canto so as to form a unique singing style of Chinese operas. We can find from the decades of singing practice that as long as we inherit traditions, learn from each other and make innovation as well as keep pace with the time, it is easy for our operas to be accepted by audiences without losing their characteristics.

In short, no matter what type of singing, we should turn the silent characters in operas into vivid artistic images through the second creation of singers and make audience immerse into the scene, sharing the same fate with characters in operas.

\section{Conclusions}

As an art form introduced from the West, although Chinese operas do not have a long history, it has already gradually formed the national tradition and the basic trend of national aesthetic awareness in terms of national aesthetic psychology while producing extensive aesthetic value and profound aesthetic impact in terms of inheriting famous pieces while they also promote the development of China's vocal art. Opera is dramatic works dominated by singing, and "singing" is a very important part. While "singing" is not purely singing like art songs, but also narrative or lyric singing in the particular environment with the development of drama plots and specific characters to express the rich thoughts and feelings of characters. Regardless of the tragedy type, hero type or love type, they all belong to "opera characters" with their inner heart and changes of emotions vividly demonstrated in the music melody, showing the particularity of this performance.

Throughout the nearly one hundred years of Chinese opera's development, Chinese operas reflect the ever changing development of the time and society through factors like music and dramas, and successfully demonstrate the fate of characters under different historical background as well as rich 
and complex inner world. In terms of music and performing, Chinese operas are always created on the premise of being open while insisting on nationalization and popularization, not only inheriting excellent Chinese culture, but also attaching importance to absorbing and learning valuable experience of Western opera art to strive for development by learning form others so as to make Chinese operas demonstrate their unique charm and style more on the opera stage worldwide.

\section{References}

[1] Ju Qihong. Contemporary Demonstration of Opera's Comprehensive Beauty [M] Beijing: Central Conservatory of Music Press, 2006:64-65，145-157，184-185， 242.

[2] Ji Xiuping. Perfect Demonstration of Hearts [M] Harbin Institute of Technology Press, 1997:120 $-122$.

[3] Editorial Department of People's Music Publishing House: Music Review — the 3rd series [M]. Beijing: People's Music Publishing House, 1980:32-41, 44-47.

[4] Meng Chaomei, Xu Zhitong, Xu Xinpu. Into the Music Hall [M]. Tianjin: Nankai University Press, 1999:155-156, 189.

[5] Chen Bingyi. Introduction to Chinese Music History [M]. Chongqing: Southwest Normal University Press, 2006:245.

[6] Hu Shiping. Discussion of New Opera Problems [M]. Beijing: China’s Drama Press, 1958.

[7] Research Institute of Music, Chinese National Academy of Arts. Collection of Music Research [M]. Beijing: Culture \& Arts Publishing House, 1985.

[8] Research Institute of Music, Chinese National Academy of Arts. Yearbook of Chinese Music [M]. Beijing: Culture \& Arts Publishing House, 1987.

[9] Jiao Juyin. Volume One of Jiao Juyin Collection. Theory of Old Opera Composition [M]. Beijing: Culture \& Arts Publishing House, 1986:284.

[10] Zhang Fenggu, Ma Huiling, Zhang Jingwei. Appreciation of Classical Chinese \& Western Music [M]. Beijing: Beijing Press, 1998: 281-282. 